\title{
Strength and Ductility of Steel Cold-Formed Section Beam to Column Bolted Connections
}

\author{
Ehab H.A.H. Aly ${ }^{(\bowtie)}$, Maged T. Hanna, and Ghada M. El-Mahdy \\ Structures and Metallic Construction Research Institute, Housing and Building \\ National Research Center (HBRC), Giza, Egypt \\ ehabbaly@yahoo.com,m_tawfick2003@yahoo.com
}

\begin{abstract}
Recently, there has been a rapid growth in the construction of low to medium rise houses and portal frames with moderate spans using steel cold-formed sections (CFS) as primary structural elements. However, the strength and stability of steel frames depend largely on the nature of the connections between their elements. This paper presents a study of the structural performance of three configurations of beam to column bolted connections of single-lipped channel CFS. In the first model, a sleeve element is used to connect the beam to the column. The sleeve element has a channel cross section with a tapered web. This enables the transmission of forces through the flanges as well as the webs. In the second model, the beam is connected to the column by a tapered gusset plate. Bolts connect the webs of the beam and column sections to the gusset plate. The third model depends on placing a knee-bracing element between the beam and the column; consequently, forces are transmitted mainly from beam to column as shear forces. Finite element models are established with the use of shell elements to model the sections while beam elements are used to model the bolted fasteners. The model is verified by comparing its results with published experimental results. The dimensions of the cross section of the members studied are $200 \mathrm{~mm}$ for the web, $60 \mathrm{~mm}$ for the flanges, and $20 \mathrm{~mm}$ for the lip. The thicknesses of the connected CFS members and connection plates are the main parameters of the study.
\end{abstract}

\section{Introduction}

Steel cold-formed sections (CFS) have traditionally been used as purlins and side girts for industrial buildings. However, recently the use of steel CFS has been extended to primary members in the construction of low to medium rise houses and portal frames with moderate spans. The use of steel CFS for columns and rafters of short and moderate span portal frames could be an economic alternative to conventional hot rolled or built up sections. The design of such frames will depend largely on the nature (rigid/semi-rigid) of the connection between the rafter and the column.

Previous research (Chung and Lau (1999); Lim and Nethercot (2004); Elkersh (2010); Öztürk and Pul (2015)) has shown that the main problem with using CFS in portal frames is the semi-rigidity of the connections due to bolt hole elongation. This reduces the moment carrying capacity of the connection (Wong and Chung (2002); Lim and Nethercot (2003); Dundu and Kemp (2006); Jackson et al. (2012)). The 
behaviour of eave and ridge joints of CFS portal frames was also studied by Dubina et al. (2004) and the study was extended to the experimental testing of full scale portal frames (Dubina et al. (2009)).

The aim of this paper is to study the structural behavior of three types of beam to column cold formed section connections. To evaluate the connection performance whether rigid or semi-rigid, the load-deflection of each connection type is compared with that of a frame having rigid corner connections. The main parameters of the study are the thickness of the channel section and the thickness of the gusset plates.

\section{Cases of Study}

The frame studied was a two-hinged frame with a span of $5 \mathrm{~m}$ and a height of $3 \mathrm{~m}$ supporting a concentrated load at mid-span as shown in Fig. 1. The parametric study was conducted on three types of connections. The first type of connection is called a lipped connection and is shown in Fig. 2(a). This type of connection depends on the fact that the connecting plate has a lip formed at it edges similar to the flanges of the cold formed sections used for the column and beam of the frame. Also, the edge of the connecting plate's flanges has a lip with the same dimension as that of the cold formed flanges. Thirty bolts are used to connect the webs of the column and beam of the frame to the connecting plate; 9 for the column and 21 for the beam. In addition to these, 10 bolts are used to connect the flange of connecting plate to the flanges of the column and beam; 3 for the column and 7 for the beam. The arrangement of bolts is shown in Fig. 2(a).

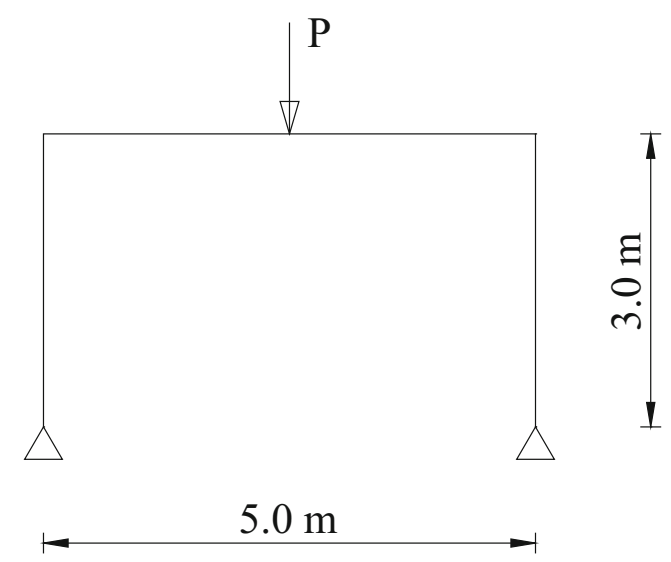

Fig. 1. Overall dimensions of the frame studied

The second type of connection is called a gusset connection and is shown in Fig. 2(b). This type of connection consists of a connecting plate that has no formed ends at its edges. The gusset plate has a tapered haunch between the column and beam of the frame. Thirty 


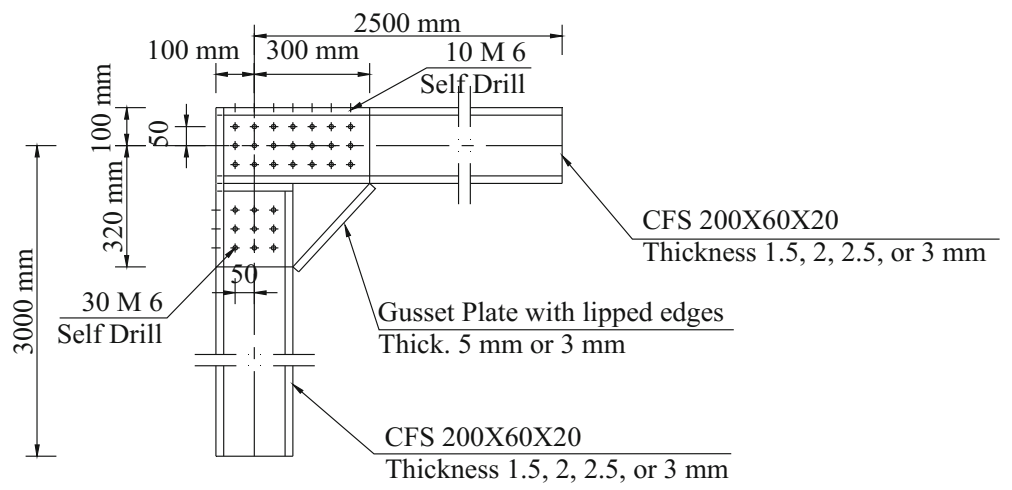

(a) Lipped connection type

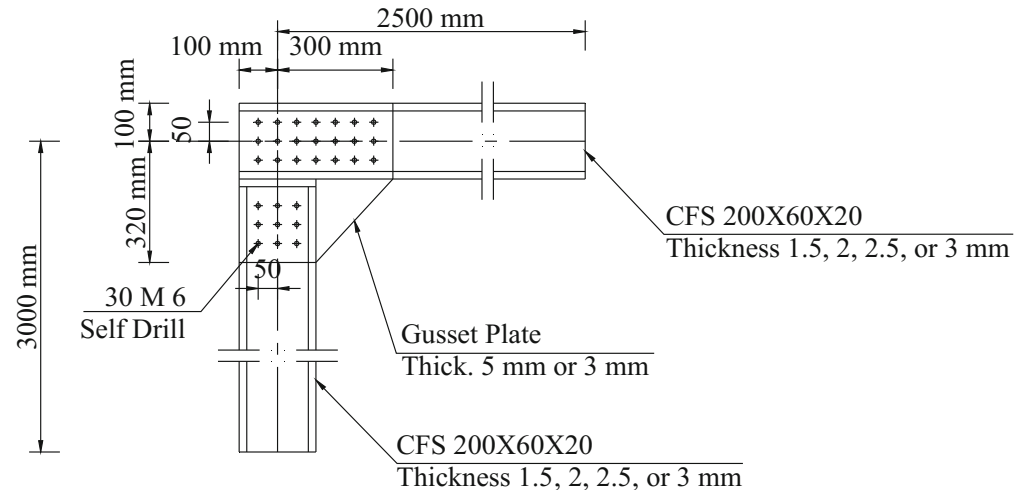

(b) Gusset connection type

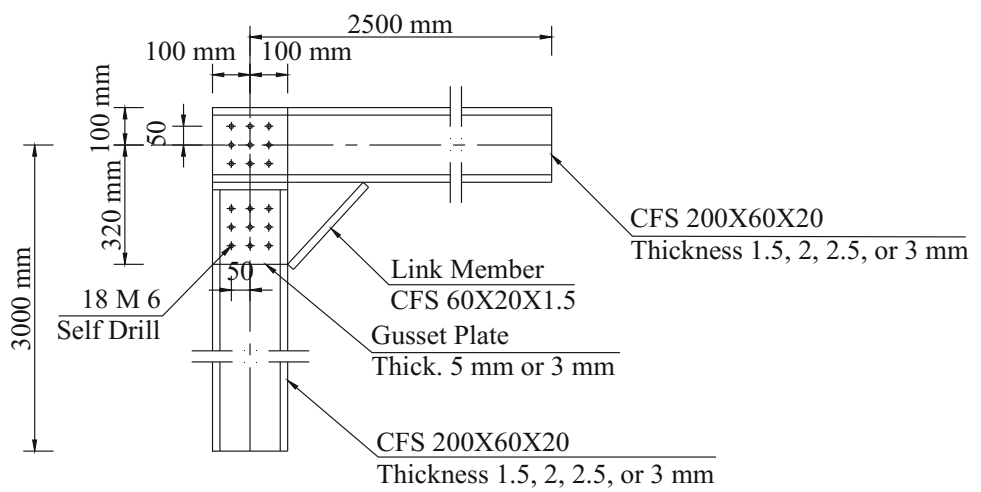

(c) Link connection type

Fig. 2. Details of the three types of connections 
bolts are used to connect the webs of the column and the beam to the connecting plate; 9 for the column and 21 for the beam. The arrangement of the bolts is shown in Fig. 2(b).

The third type of connection is call a link connection and is shown in Fig. 2(c). This type of connection consists of a connecting plate and a $\mathrm{C}$-section used as a link member. The link member is used to connect the column with the beam. In addition, the gusset plate is used to connect the column with the beam. Eighteen bolts are used to connect the webs of the column and beam to the connecting plate; 9 for the column and 9 for the beam. The arrangement of bolts is shown in Fig. 2(c).

The cross-sectional dimensions of the cold formed section used were $200 \mathrm{~mm}$ depth, $60 \mathrm{~mm}$ flange width, and $20 \mathrm{~mm}$ lip. The thicknesses of the cold formed sections used were $1.5,2.0,2.5$, and $3.0 \mathrm{~mm}$, and the connecting plate's thicknesses used were 1.5 and $3.0 \mathrm{~mm}$.

\section{Finite Element Model}

The finite element models consisted of shell elements to represent the three types of connections as shown in Fig. 3, as well as, the cold formed sections. The crosssectional dimensions of the cold formed section that was modelled are $200 \mathrm{~mm}$ depth, $60 \mathrm{~mm}$ flange width, and $20 \mathrm{~mm}$ lip. The thicknesses of CFS were varied as follows; $1.5,2.0,2.5$, and $3.0 \mathrm{~mm}$. While the thicknesses of the gusset plates used in the connections were 1.5 and $3.0 \mathrm{~mm}$.

\subsection{Material Behaviour}

A linear elastic-perfectly plastic material model was used to model the steel. The material properties were taken from the Egyptian Code of Practice for Steel Construction and Bridges (ECP (2001)). The nominal yield stress, $F_{y}$, of steel was taken as $2.4 \mathrm{t} / \mathrm{cm}^{2}(240 \mathrm{MPa})$ and the ultimate strength, $F_{u}$, was taken as $3.6 \mathrm{t} / \mathrm{cm}^{2}(360 \mathrm{MPa})$ to represent Grade St. 37, and the modulus of elasticity, $E$, was taken as $2100 \mathrm{t} / \mathrm{cm}^{2}(210$ $\mathrm{GPa})$.

\subsection{Geometry, Meshing, and Finite Elements}

In the ANSYS launcher (2007), the finite element (FE) model was formed using SHELL181 elements to build and shape the structural elements. The SHELL181 element is suitable for analysing thin to moderately-thick shell structures. It is a 4-node element with six degrees of freedom at each node: translations in the $\mathrm{X}, \mathrm{Y}$, and $\mathrm{Z}$ directions, and rotations about the $\mathrm{X}, \mathrm{Y}$, and $\mathrm{Z}$ axes. In addition, the BEAM4 element was used to model the bolts. The bolts have a diameter of $6 \mathrm{~mm}$. The column of the frame has a height of $3000 \mathrm{~mm}$ and the span of frame beam is $5000 \mathrm{~mm}$. Only half the frame was modelled to simplify the analysis. The meshing of connection type 1 (lipped) consisted of 2268 nodes and 2165 elements. While the meshing of connection type 2 (gusset) consisted of 2885 nodes and 2774 elements. Also, the meshing of connection type 3 (link) consisted of 2324 nodes and 2032 elements. Six stiffeners were 


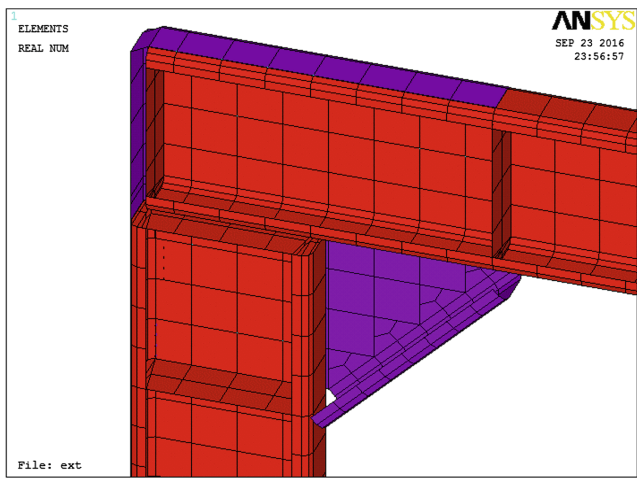

(a) Lipped connection type with 2268 nodes and 2165 elements

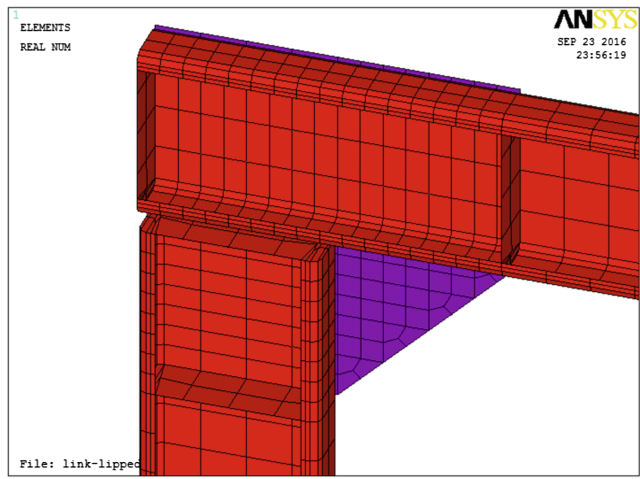

(b) Gusset connection type 2885 nodes and 2774 elements

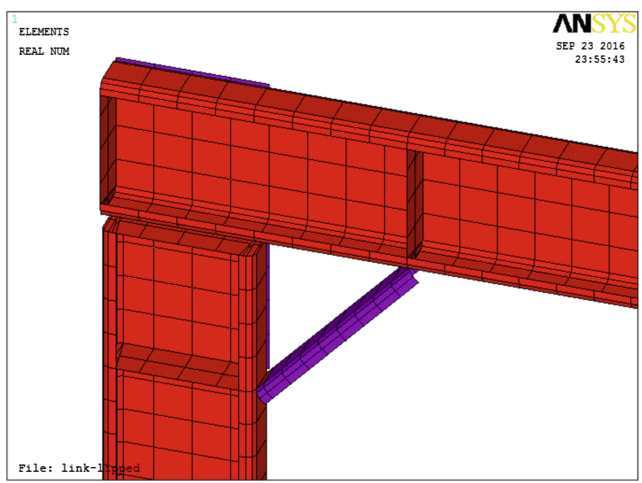

(c) Link connection type with 2324 nodes and 2032 elements

Fig. 3. Finite element models of the three types of connections 
added to the model, three for the column and three for the half beam, at the supports and under the concentrated load to avoid any local deformations. Figure 3 shows the finite element models of the three types of connections.

\subsection{Boundary Conditions and Loading}

The column of the frame was supported as a hinged support at the center-line of the base cross section. The end of the half beam under the load was restrained against lateral translation out of the plane of the frame and rotation in the plane of the frame. The loading was simulated to represent the applied force at the half span of frame in the negative $\mathrm{Y}$ direction. The concentrated load was distributed on the end plate nodes at the half span of the frame. The applied load was controlled by a force rating of 1.0, 0.5, and $5.0 \mathrm{kN} / \mathrm{s}$ as the normal, minimum, and maximum increments, respectively.

\subsection{Verification of the Connection Model}

To verify the results of this research a comparison was made between the modelling used in this research and the experimntal test results of Pernes and Nagy (2012). Figure 4 represents the reults of the comparison. The comparison shows that finite element results gave an ultimate load similar to the experimental results with bolts in the flange KIS-FB-M varying by approximately $4 \%$. However, there are clear differences between the experimental results and the finite element results in that the experimental results show more flexibility before reaching the ultimate load possibly due to several factors such as slippage in the test set-up and also existing tolerances between the bolts and the bolt holes as well as bolt hole elongation. Also, Pernes and Nagy (2012) reported that the failure of the connection was due to local buckling about bolt holes which formed a local plastic mechanism which caused the drop in the load carrying capacity of the experimental results.

\subsection{Rigid Frame Model}

The model developed by Hanna (2014) to study the structural performance of CFS rigid frames was used here to evaluate the behaviour of the different connection types. The frame, shown in Fig. 5(a), is modelled numerically by the isoparametric shell element "Shell4T" that is available in the COSMOS/M (2000) finite element package.

The meshing density is chosen so that the element aspect ratio on average equals one. At the column bases the four corners of the lipped channel section are prevented from translation along the $\mathrm{Z}$ direction, in addition, nodes that lie on the axis that passes through the mid-web height of the section are prevented from translation in the $\mathrm{X}, \mathrm{Y}$, and $\mathrm{Z}$ directions, as shown in Fig. 5(b). These boundary conditions allow the column bases to rotate about the $\mathrm{Z}$-axis, and prevent torsion about the $\mathrm{Y}$ axis. To prevent the out of plane deformation of the frame members, nodes at the flange web junction are prevented from translation in the $\mathrm{Z}$ direction. 


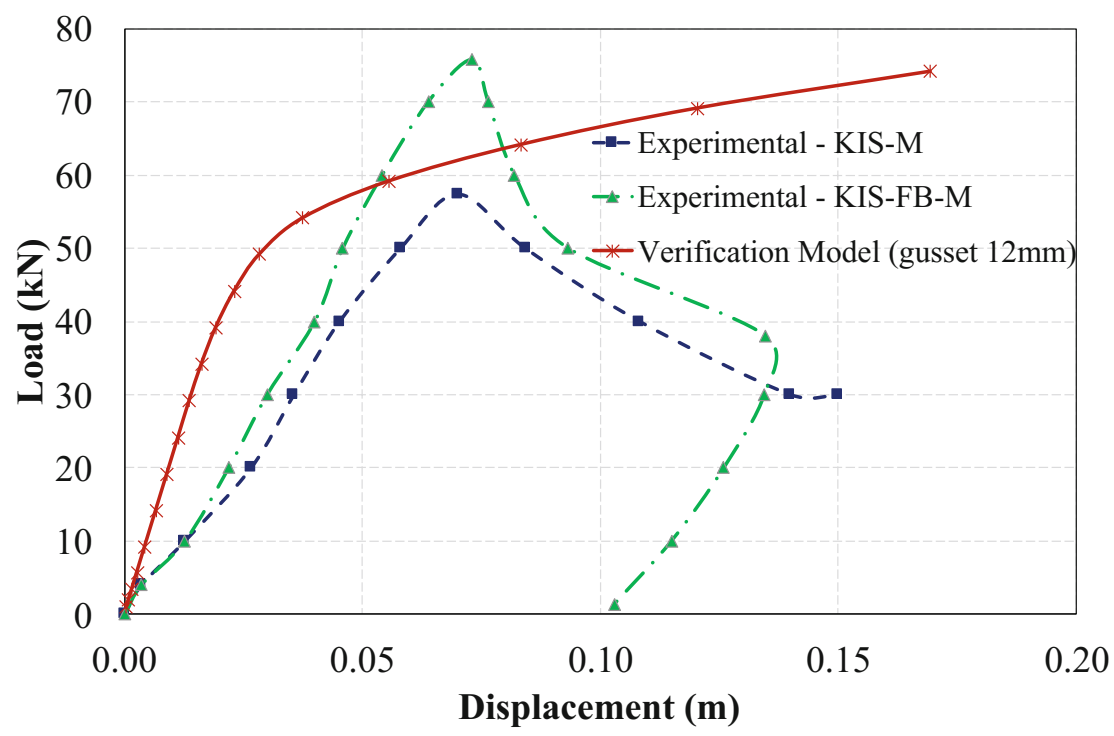

Fig. 4. Comparison between the results of the verification model and experimental test results (Pernes and Nagy 2012)

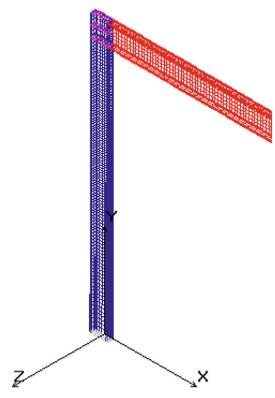

(a) Frame model

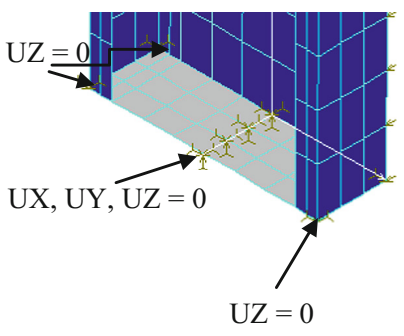

(b) Base connection

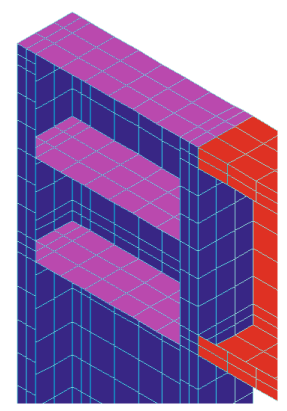

(c) Corner connection

Fig. 5. Finite element model of rigid frame

The connection between the beam and the column is modelled as depicted in Fig. 5 (c). The column section is continued, and the nodes at the intersection of the beam and the column are merged together. In addition, to insure full rigid connection, three horizontal stiffeners are added. Two stiffeners are placed at the beam flanges level, and the third one at the beam web mid-height level. The material is assumed to be elastic-perfectly plastic obeying the von-Mises yield criterion. The Newton-Raphson iterative technique along with the tangential stiffness matrix was implemented to solve the set of non-linear equations at each load increment. 


\section{Results}

\subsection{Behaviour of the Different Types of Connections}

The link and gusset type connections showed very similar results from the point of view of the ultimate load. While the deflection in the link type connection was less than that of the gusset type connection. This means that the rigidity of the link connection is greater than that of the gusset connection. The lipped type connection has the highest ultimate load value compared to the link and gusset type connections. In addition, the lipped connection has the greatest deflection, which means that the rigidity of the lipped connection is less than that of the link and gusset connections.

\subsection{Ultimate Loads and Modes of Failure of Each Connection}

All connection types, which were analyzed using the ANSYS program (full modelling of connection), had the same mode of failure which was under the concentrated load. The failure occurred due to the model reaching the ultimate strength of the beam under the load, which was at the mid-span of the frame. The stress in the beam was very high at the connection but was still less than the stress at the point load, as shown in Fig. 6 for the link connection. In addition, the stress in the column of the frame was relatively low, compared to the stress generated in the beam of the frame. The maximum stress in the column was at the third height of the column from the top. Some high stresses appeared in the connection plate but these stresses were still under the ultimate value. The stresses in the connection plates play an important role in reducing the rigidity of the connection between the column and beam of the frame.

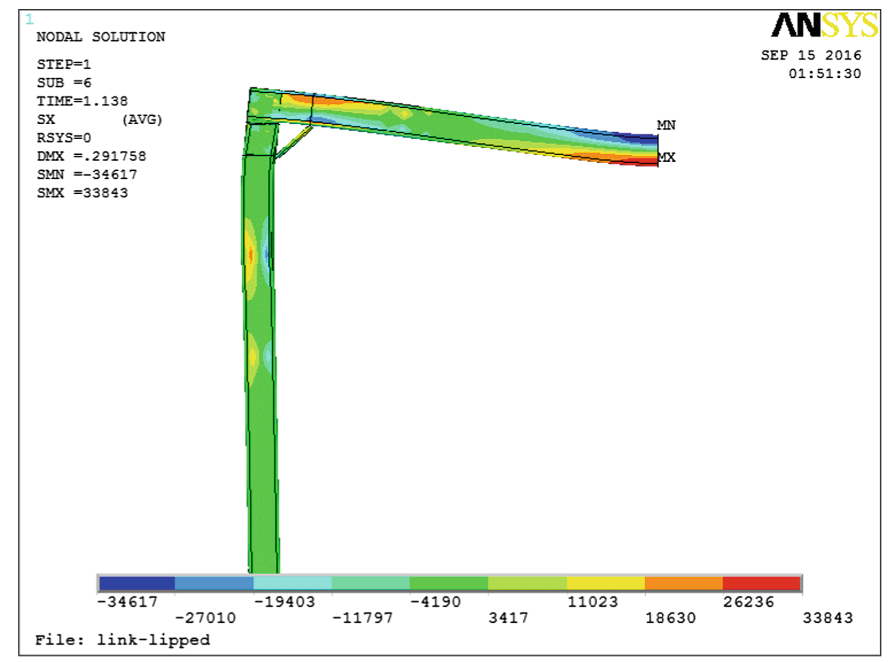

Fig. 6. Failure of link connection with CFS of thickness $2.5 \mathrm{~mm}$ and gusset plate of thickness $3.0 \mathrm{~mm}$ 
Table 1. Ultimate loads of the three types of connection $(\mathrm{kN})$

\begin{tabular}{l|l|l|l|l|l|l}
\hline Member thickness, $t_{1}(\mathrm{~mm})$ & \multicolumn{2}{l|}{$\begin{array}{l}\text { Connection } \\
\text { thickness, } \\
\end{array}$} & \multicolumn{4}{l}{$\begin{array}{l}\text { Connection } \\
\text { thickness, }\end{array}$} \\
\cline { 2 - 8 } & Lipped & Gusset & Link & Lipped & Gusset & Link \\
\hline 1.5 & 20.5 & 16.0 & 18.3 & 20.0 & 17.0 & 19.8 \\
\hline 2.0 & 26.7 & 19.4 & 24.4 & 26.3 & 22.8 & 26.5 \\
\hline 2.5 & 29.7 & 25.0 & 27.4 & 35.0 & 27.5 & 32.3 \\
\hline 3.0 & 35.0 & 28.4 & 30.9 & 42.5 & 32.5 & 39.9 \\
\hline
\end{tabular}

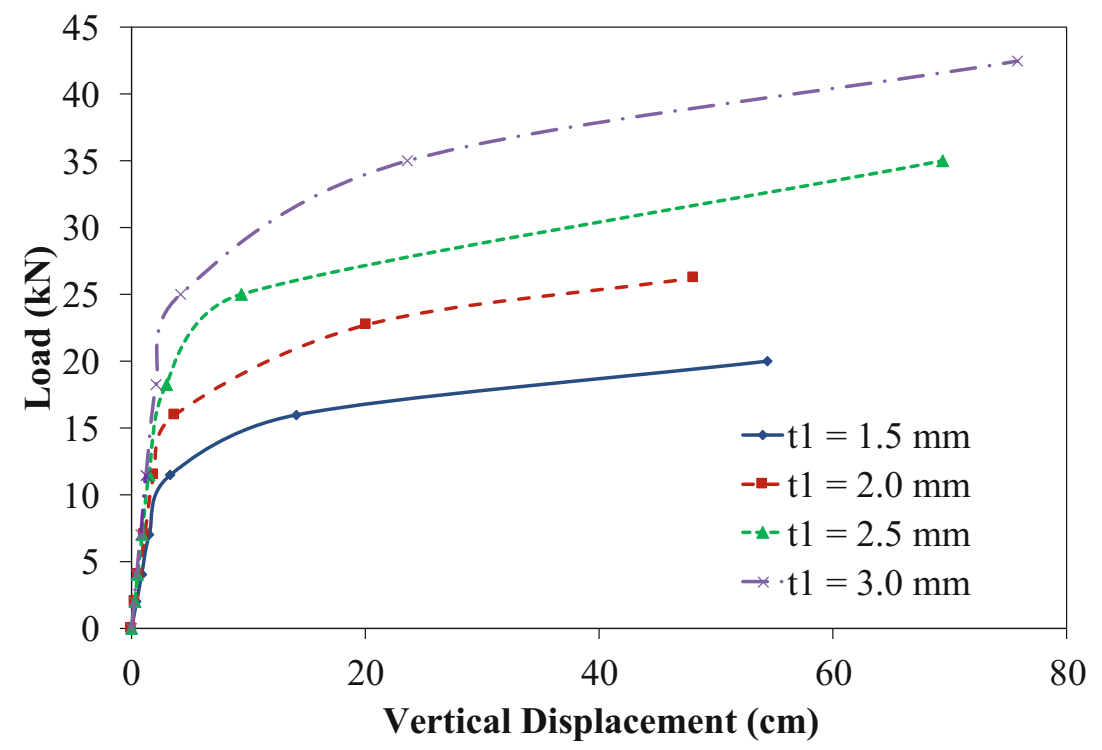

Fig. 7. Load-vertical displacement (lipped connection), $t_{2}=3.0 \mathrm{~mm}$

The ultimate loads of each connection are listed in Table 1 for the different thicknesses of the member to be connected, $t_{1}$, and the two connection thicknesses, $t_{2}=1.5$ and $3.0 \mathrm{~mm}$. The applied loads are plotted with respect to the vertical displacement of the web mid-point under the point of application of the load for the three types of connections in Figs. 7, 8 and 9. These figures show the results of the connections with a thickness $t_{2}=3.0 \mathrm{~mm}$. The findings reflect that, for the three types of connections, all the curves match together in the early elastic stage, and then at a load of approximately half the ultimate loads an excessive deformation occurs before failure. In addition, the lipped connection has the highest ultimate load compared with the other two connections. However, the gusset connection has the lowest ductility. 


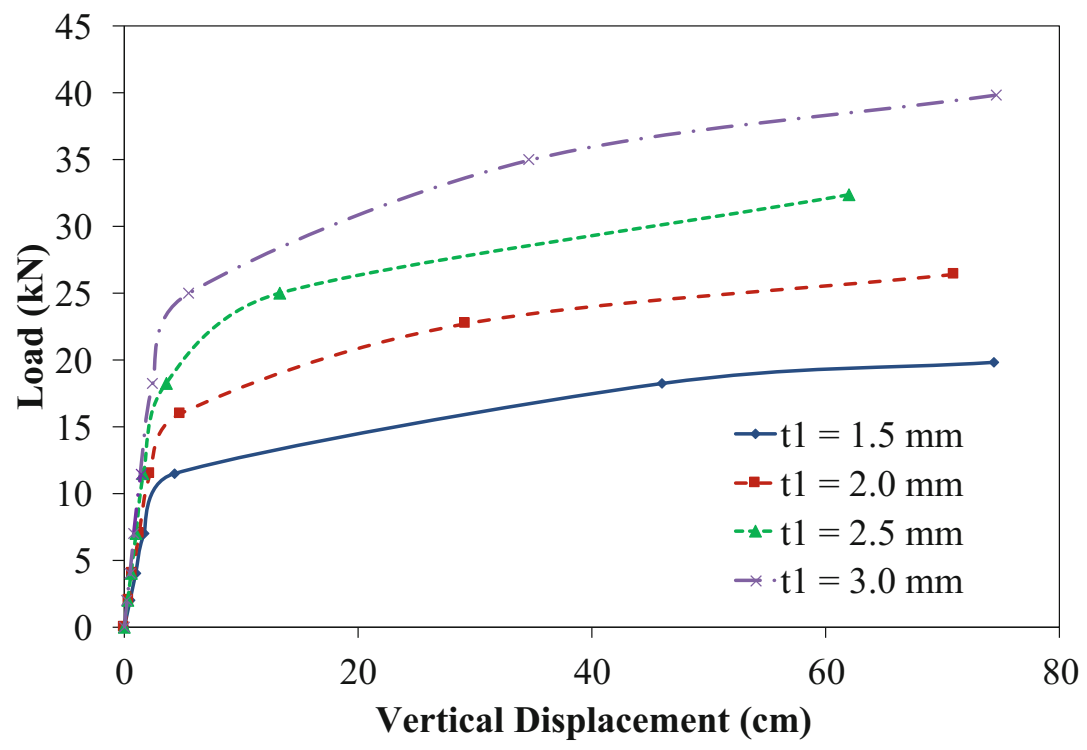

Fig. 8. Load-vertical displacement (link connection), $t_{2}=3.0 \mathrm{~mm}$

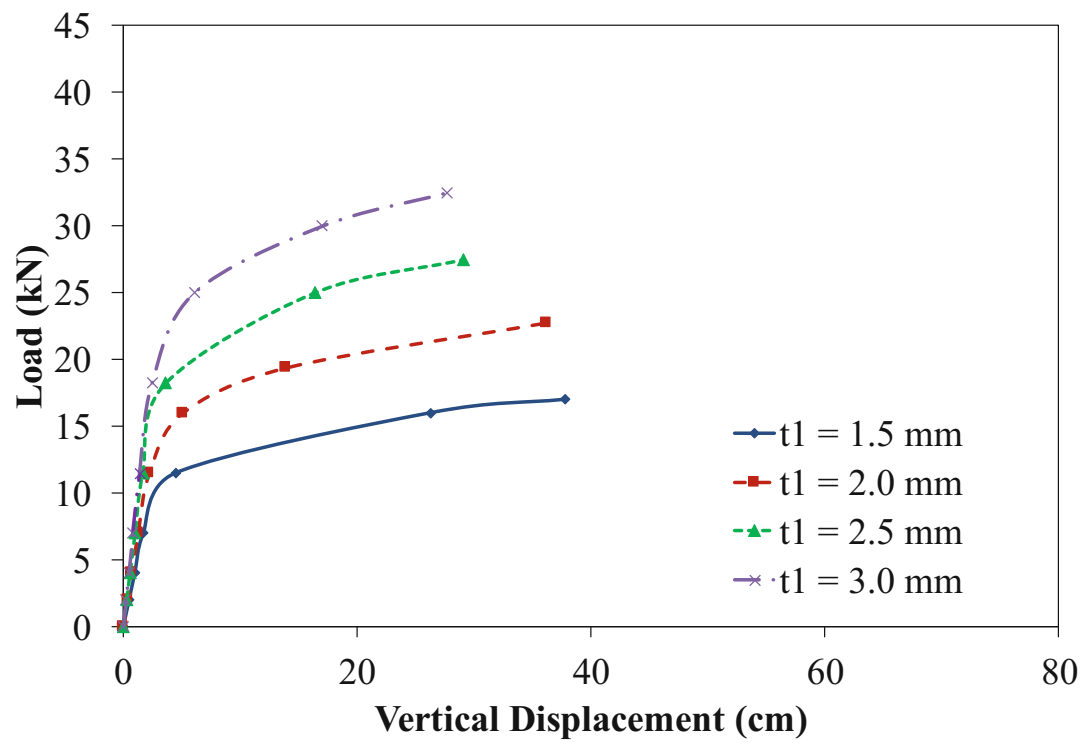

Fig. 9. Load-vertical displacement (gusset connection), $t_{2}=3.0 \mathrm{~mm}$ 


\subsection{Comparison with Rigid Frame Response}

For all studied rigid frames, local buckling in the beam middle section characterizes the failure mode, as shown in Fig. 10, and the deformed shape was as shown in Fig. 11. The load deflection curves of the three types of connection match with that of the rigid frame in the early linear elastic stage. After that, the connections exhibit large deformations compared with that of the rigid frame as shown in Figs. 12, 13, 14 and 15 indicating that the connections are semi-rigid.

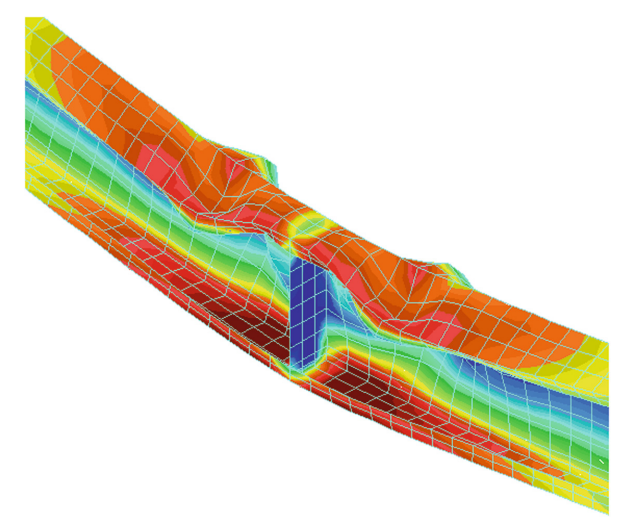

Fig. 10. Local buckling at the beam mid-span section

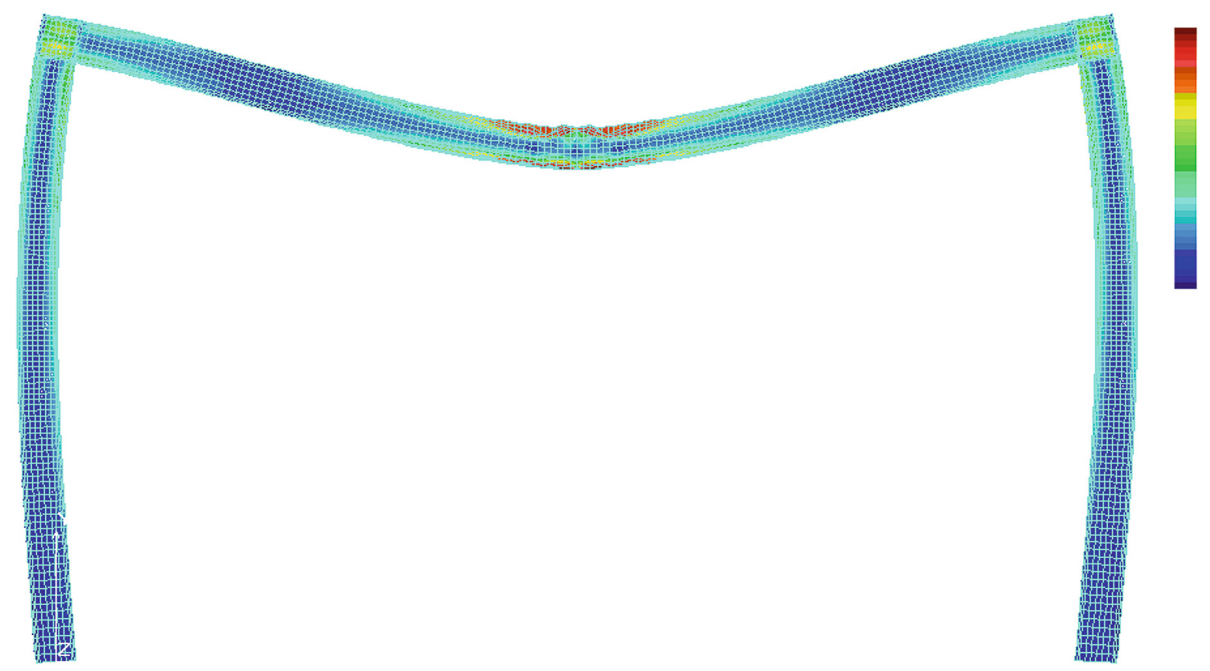

Fig. 11. Deformed shape and stresses at ultimate loads of the rigid frame model 


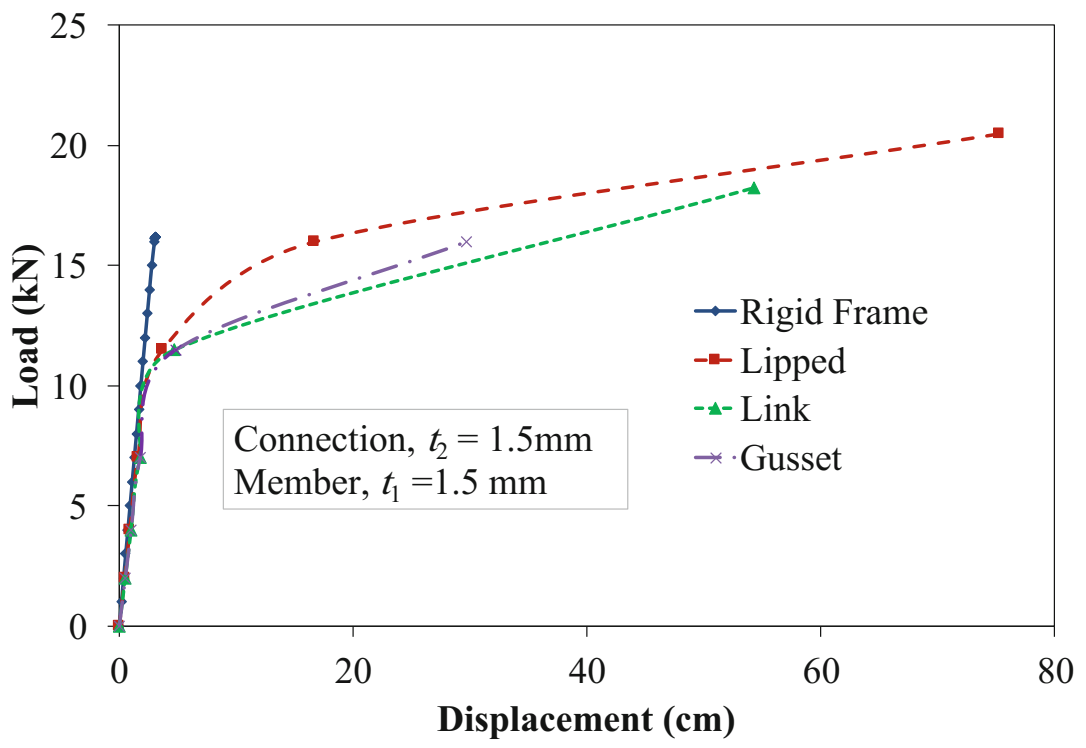

Fig. 12. Comparison of load-deflection curves for $1.5 \mathrm{~mm}$ thick CFS and $1.5 \mathrm{~mm}$ thick connection

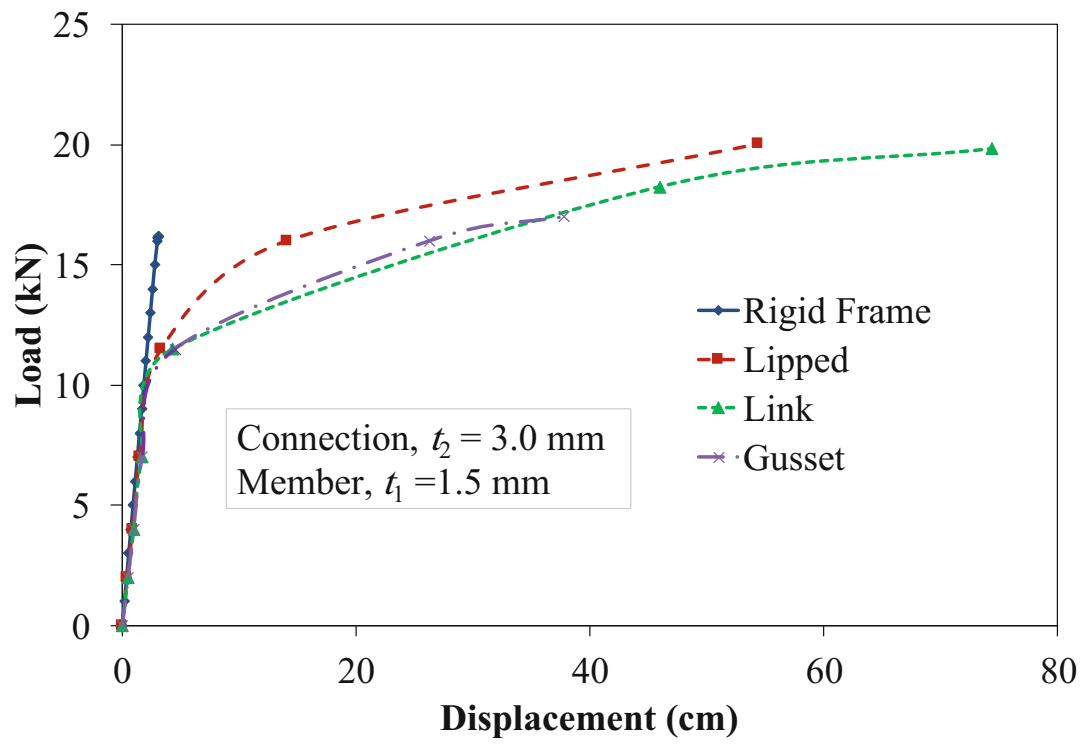

Fig. 13. Comparison of load-deflection curves for $1.5 \mathrm{~mm}$ thick CFS and $3.0 \mathrm{~mm}$ thick connection 


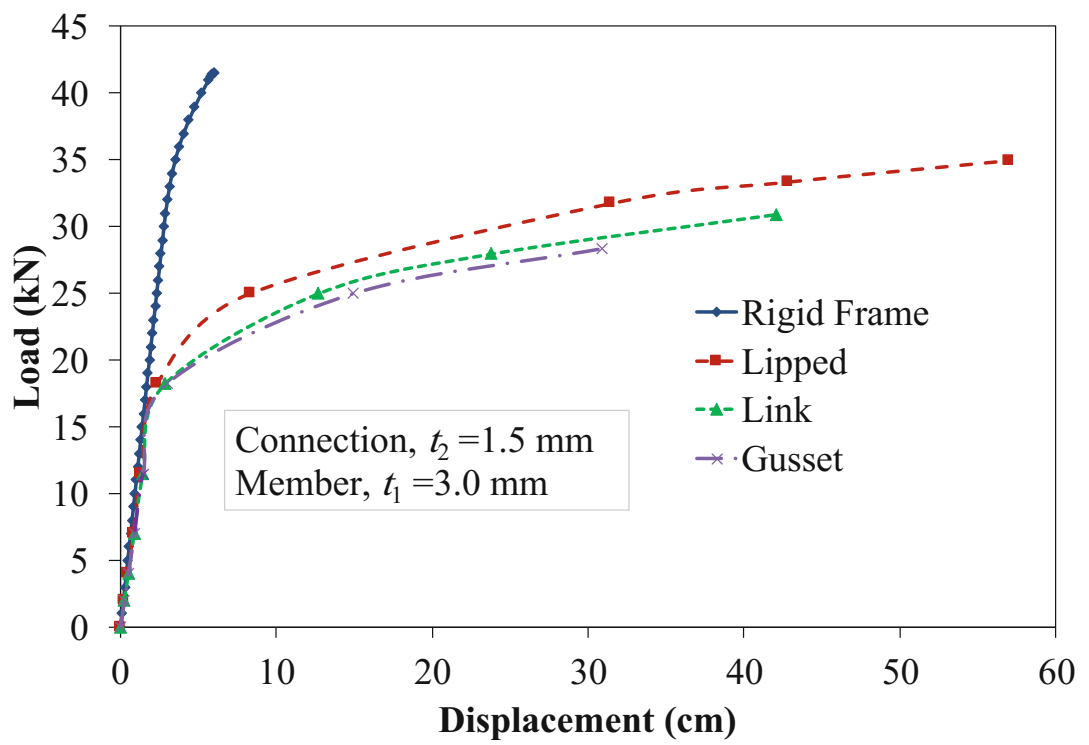

Fig. 14. Comparison of load-deflection curves for $3.0 \mathrm{~mm}$ thick CFS and $1.5 \mathrm{~mm}$ thick connection

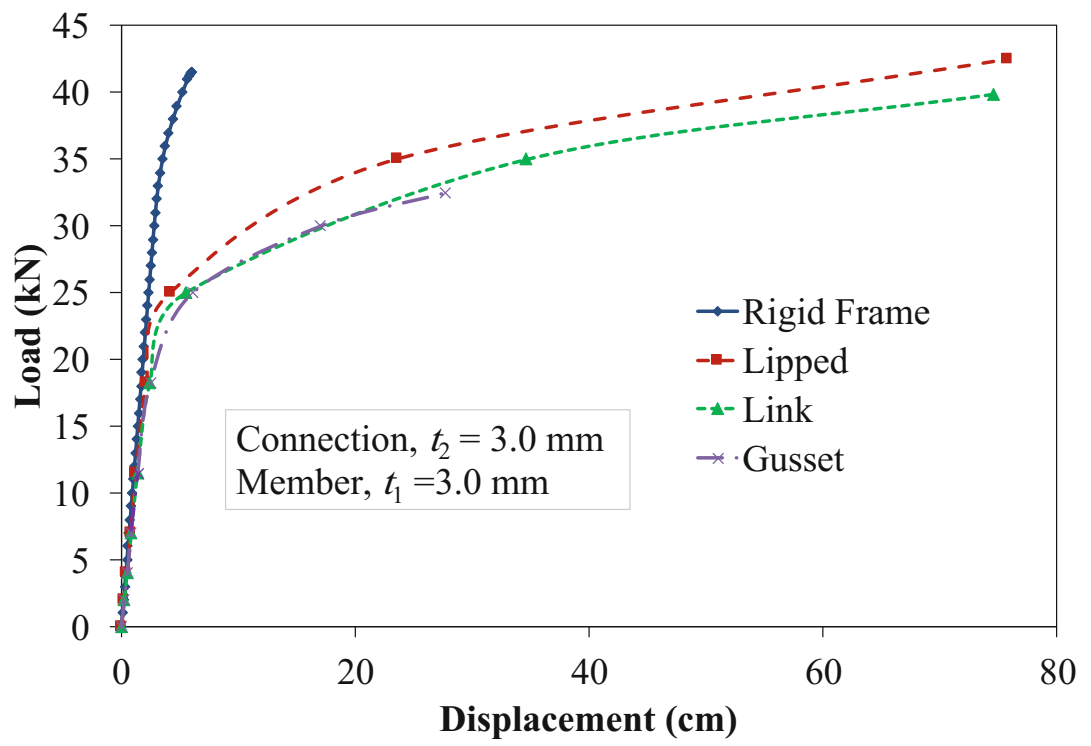

Fig. 15. Comparison of load-deflection curves for $3.0 \mathrm{~mm}$ thick CFS and $3.0 \mathrm{~mm}$ thick connection 


\section{Conclusions}

From the parametric study of the three types of connections, it was found that the lipped connection gives higher loads compared with the other two connections and the gusset connection showed the least ductility.

The results show that the thickness of the connecting elements should not be less than $70 \%$ of the thickness of the connected members in order to reach the same ultimate loads of the rigid frame assumption. For example, when using connecting elements with a thickness of $1.5 \mathrm{~mm}$, the ultimate loads of thicker members $(2.5 \mathrm{~mm}$ and $3.0 \mathrm{~mm}$ ) decreases. However, when using thick connecting elements $(3.0 \mathrm{~mm})$, the ultimate loads of all connection types are approximately equal to that of the rigid frame assumption (or higher).

For all connection types the deformation at the ultimate loads are much higher than that of the rigid frame assumption. This means that if we assign a maximum displacement of $L / 200$ due to live load (i.e., approximately $10 \mathrm{~cm}$ due to total ultimate load) as a limit of failure, the ultimate loads of all connection types will achieve about $50 \%$ of the rigid frame capacity.

\section{References}

ANSYS Launcher 11. ANSYS Inc., Canonsburg (2007). ansys.com

Chung, K.F., Lau, L.: Experimental investigation on bolted moment connections among cold formed steel members. Eng. Struct. 21(10), 898-911 (1999)

COSMOS/M V2.6. Structural Research and Analysis Corporation, S.R.A.C, Los Angles (2000)

Dubina, D., Stratan, A., Ciutina, A., Fulop, L., Nagy, Z.: Performance of ridge and eaves joints in cold-formed steel portal frames. In: Proceedings of the 17th International Conference on Cold-Formed Steel Structures, Orlando, Florida, U.S.A (2004)

Dubina, D., Stratan, A., Nagy, Z.: Full-scale tests on cold-formed steel pitched-roof portal frames with bolted joints. Adv. Steel Constr. 5(2), 175-194 (2009)

Dundu, M., Kemp, A.R.: Strength requirements of single cold-formed channel sections connected back-to-back. J. Constr. Steel Res. 62, 250-261 (2006)

ECP: Egyptian Code of Practice for Steel Construction and Bridges - Allowable Stress Design (2001)

Elkersh, I.: Experimental investigation of bolted cold formed steel frame apex connections under pure moment. Ain Shams Eng. J. 1, 11-20 (2010)

Hanna, M.T.: Structural performance of steel cold formed sections portal frames. In: Proceedings of the 7th European Conference on Steel and Composite Structures, Napoli, Italy (2014)

Jackson, C., Wrzesien, A.M., Johnston, R.P., Uzzaman, A., Lim, J.B.P.: Effect of reduced joint strength and semi-rigid joints on cold-formed steel portal frames. In: Proceedings of the 6th International Conference of Coupled Instabilities in Metal Structures, Glasgow, U.K. (2012)

Lim, J.B.P., Nethercot, D.A.: Ultimate strength of bolted moment connections between cold-formed steel members. Thin-Walled Struct. 41, 1019-1039 (2003)

Lim, J.B.P., Nethercot, D.A.: Stiffness prediction for bolted moment connections between cold-formed steel members. J. Constr. Steel Res. 60, 85-107 (2004)

Öztürk, F., Pul, S.: Experimental and numerical study on a full scale apex connection of cold-formed steel portal frames. Thin-Walled Struct. 94, 79-88 (2015) 
Pernes, P.M., Nagy, Z.: FE modeling of cold-formed steel bolted joints in pitch-roof portal frames. Acta Tech. Napocensis: Civ. Eng. Archit. 55(3) (2012)

Wong, M.F., Chung, K.F.: Structural behaviour of bolted moment connections in cold-formed steel beam-column sub-frames. J. Constr. Steel Res. 58(2), 253-274 (2002) 